\title{
Sperm Hyperactivation and Capacitation Induced By Light Stimuli in Cryopreserved Semen
}

\section{SOTO ${ }^{1}$, M.A. FUENTES ${ }^{1}$, G. NAVIDAD ${ }^{1}$, R.N. MEZA ${ }^{1}$, L.A. MANDUJANO ${ }^{2}$, A.G. SALAZAR ${ }^{1}$, C. FERNÁNDEZ ${ }^{3}$, C. GARCÍA ${ }^{4}$,Y.E. FELIPE-PÉREZ ${ }^{4}$ AND D. OSORIO-GONZÁLEZ ${ }^{*}$.}

${ }^{1}$ Laboratorio de Biofísica Molecular de la Facultad de Ciencias. Universidad Autónoma del Estado de México.

${ }^{2}$ Laboratorio de Diseño y Modelado Biofísico Molecular de la Universidad

Mexiquense, S. C.

${ }^{3}$ Clinica Fertilidad "Biología de la Reproducción” del Hospital Materno Perinatal

"Mónica Pretelini Sáenz" Adscripción

${ }^{4}$ Laboratorio de Biología de la Reproducción de la Facultad de Medicina Veterinaria y

Zootecnia. Universidad Autónoma del Estado de México

\section{Email: dog@uaemex.mx}

Published online: August 07, 2017

The Author(s) 2017. This article is published with open access at www.chitkara.edu. in/publications

\begin{abstract}
In mammals, such as rabbits, there are some factors involved in a possible fertilization, from complex changes in the membrane of the sperm to obstruction or non-existent of vas deferens, which creates problems in the number and quality of sperm. In this work, we report effects of rabbit sperm motility and capacitation of cryopreserved semen samples under light stimuli. The sperm velocities were correlated with the percentage of capacitated and non-capacitated sperm seen with a fluorescent dye. Consequently, we analyzed the specific correlations between irradiation times, supplied energy and fertility parameters.
\end{abstract}

Keywords: Sperm capacitation, Fertility, light stimuli

\section{INTRODUCTION}

Sperm maturation process takes place once sperm gets out of the testis, continues along their passage through the epididymis and finish when they have lost the cytoplasmic droplet and have acquired motility. When sperm arrives at the deferent duct, they are ready to be ejaculated and deposited inside the female's reproductive tract, where they must interact with the oviductal tissue to acquire hyper-motility that will help them reach the liberated oocyte.

Journal of Nuclear

Physics, Material Sciences, Radiation and Applications Vol-5, No-1, Feburary 2017 pp. 157-167 
Soto, V

Fuentes, MA

Navidad, G

Meza, RN

Mandujano, LA

Salazar, AG

Fernández, C

García, C

Felipe-Pérez, YE

Osorio-González D
Once they encounter the oocyte, sperm must suffer the acrosome reaction to complete the fertilization process.

When it comes to humans, some studies show that $15 \%$ of the couples, in which the fertility status is unknown and have been maintaining unprotected sexual intercourse, will have difficulties to conceive. Approximately in $30 \%$ of couples, infertility is due to the male factor, and $20 \%$ is a combination of both: female-male; this means that male factor is involved in near $50 \%$ of the infertile couples [1,2]. However, there are many options for assisted reproductive treatment, among them, the cryopreservation of semen is a useful procedure to keep the fertilization ability in men with ailing. In the case of non-human animals, the infertility is a serious problem because of pollution factors and environmental stress due to climate change. Increasingly there are more endangered species as result of a drastic decrease in their reproductive capacity due to harmful effects on their metabolism caused by pollutants in the air like nitrogen dioxide, sulfur dioxide and carbon monoxide $[14,15,16]$.

The techniques of sperm freezing have been very useful for assisted reproduction, however, the integrity of the sperm show notable changes after being subjected to a cryopreservation process. The cooling, freezing and unfreeze involved in the cryopreservation, contribute to the structural damages in the sperm, mainly alterations in the plasmatic membrane, acrosome and mitochondria have been reported. As result of this damages, the fertility potential of cryopreserved sperm is reduced [5].

Motility is one of the most important parameters of seminal quality and is evaluated through curvilinear velocity (VCL), average path velocity (VAP), straight line velocity (VSL) and linearity (LIN) $[3,5,6]$. These parameters increase with sperm capacitation, that is acquired during their journey through the female tract and is characterized by a flagellar movement in which a wide flagellar beating and a lateral head displacement are observed, known as hyperactivation. For achieving artificial fertilization, an in vitro sperm capacitation procedure must be performed with the help of culture medium and human albumin supplementation, different hormones, and enrichment medium [9]. Currently, there are several techniques used for in vitro sperm capacitation. Viable spermatozoa with acceptable motility obtained with this procedure can be used in assisted reproduction techniques, such as intrauterine insemination, in vitro fertilization or intracytoplasmic injection, due to the minimal number of gametes that are required to carry out the reproductive procedures to increase the probability of success [8].

Electromagnetic irradiation is a widely-used tool to stimulate biological systems energetically. Depending on the wave length, dosage, and the state of the irradiated tissue, a laser beam over a tissue can induce an anti-inflammatory 
effect, pain reduction, and the acceleration of cell proliferation, among others $[5,7]$.

In previous studies, different cell types have been exposed to low-energy light radiation, several have used lasers to immobilize spermatozoa, but very few have used it to stimulate them [3]. It has been proven that low-energy laser radiation over spermatozoa can increase the motility of these [5]. The radiation effects are more outstanding when cells or tissues are under stress (due to a lack of oxygen, glucose, among others) [3]. The biological mechanisms of interaction with the low energy laser are not entirely known. It is known; however, that different cell types do not behave the same way when they are irradiated by the same wavelength [5].

It is very recurrent to use a Computer-Assisted Sperm Analysis system (CASA) to determine the effect that a laser beam has on the different motility parameters of the spermatozoa, as it provides higher objectivity, sensitivity, and reliability than the direct observation analysis method [4], since it reduces human error [11]. Conventional CASA systems allow the determination of sperm movement characteristics but do not incorporate dynamic properties such as accelerations, viscosity, and shear stress.

\section{METHOD}

\subsection{Semen donors, housing, and feeding}

All animals were kept in individual wired cages $(60 \times 80 \times 40 \mathrm{~cm})$ and were maintained under farm conditions, with natural lighting and temperature conditions. Feed and water were administered ad libitum, using metal feeders, giving commercial brand pellets for rabbit maintenance, while automatic nipples provided water. The Institutional Bioethical Committee approved all management conditions.

\subsection{Semen extraction and cryopreservation}

Semen of 13 sexually matured bucks of 18 months of age, and previously trained, was collected, using an artificial vagina. Semen collection was performed twice a week, during the spring season (March to May). The semen evaluation was performed on all semen samples, but only those that covered the inclusion criteria were incorporated into de semen pool (semen parameters for inclusion criteria: $80 \%$ motility or above, $80 \%$ viability or above, and less than $20 \%$ of morpho-anomalies.

Semen pool was diluted in a 1:6 ratio with a commercial semen diluent, which was prepared as follows: 60\% distilled water, 20\% egg-yolk and 
Soto, V

Fuentes, MA

Navidad, G

Meza, RN

Mandujano, LA

Salazar, AG

Fernández, C

García, C

Felipe-Pérez, YE

Osorio-González D
20\% Triladyl ${ }^{\mathrm{TM}}$ (Minitube, Germany). The first step of dilution was done in a 1:1 ratio, having both, semen and diluent tempered at $37 \mathrm{C}^{\circ}$, then, the rest of the diluent was added after 5 minute periods, dividing the final diluent volume into three equal portions, which were gradually mixed with the semen sample, however, the dilution temperature was gradually lowered to ambient temperature (about $20 \mathrm{C}^{\circ}$ ).

Once the final volume was completed, diluted semen was packed into $0.5 \mathrm{cc}$ plastic straws; then they were kept under refrigeration for 40 minutes at $4 \mathrm{C}^{\circ}$. After that, cryopreservation was done by exposing semen straws to nitrogen vapor, placing them $5 \mathrm{~cm}$ above liquid nitrogen for $10 \mathrm{~min}$, then, straws were plunged into liquid nitrogen and finally kept into cryogenic tanks, for further evaluation.

\subsection{Semen thawing}

Thawing was carried out by withdrawing the straws from the cryogenic tank and keeping the straws at room temperature for a few seconds. Then, they were placed in a $37 \mathrm{C}^{\circ}$ water bath, the straws were cut, and the semen was deposited in $1.5 \mathrm{ml}$ plastic tubes, to proceed with the sample irradiation and proper evaluation.

\subsection{Semen samples irradiation}

A Fermion I continuous wave solid state (CW) laser with a 405 nanometers wavelength and 20 to $100 \mathrm{~mW}$ variable power, was used to irradiate the semen samples. In the present study, a power of $70 \mathrm{~mW}$ was used, and the samples were divided to be exposed to radiation into two groups: The first group was irradiated for 60 seconds (4.2 joules) and the second group for 90 seconds (6.3 joules). In all cases, $15 \mu \mathrm{L}$ semen samples were placed on glass slides, which were perpendicularly irradiated on an effective $4.5 \mathrm{~cm}^{2}$ surface, while being placed inside a thermoregulatory chamber at $37^{\circ} \mathrm{C}$. Density energy in each sample irradiated was $15.5 \mathrm{~mW} / \mathrm{cm}^{2}$. The control group was not irradiated but were subjected to the same experimental conditions as other groups. In contrast, two treatment groups were irradiated, under the same conditions, but samples of $20 \mu \mathrm{L}$ were placed over a glass slide, inside the chamber. After that, semen evaluation with the CASA software, as well as the capacitation status was carried out.

\subsection{Sperm capacitation test}

Cryopreservation promotes plasma membrane as well as cytoskeleton changes, which induced what is called cryo capacitation; therefore, the capacitation 


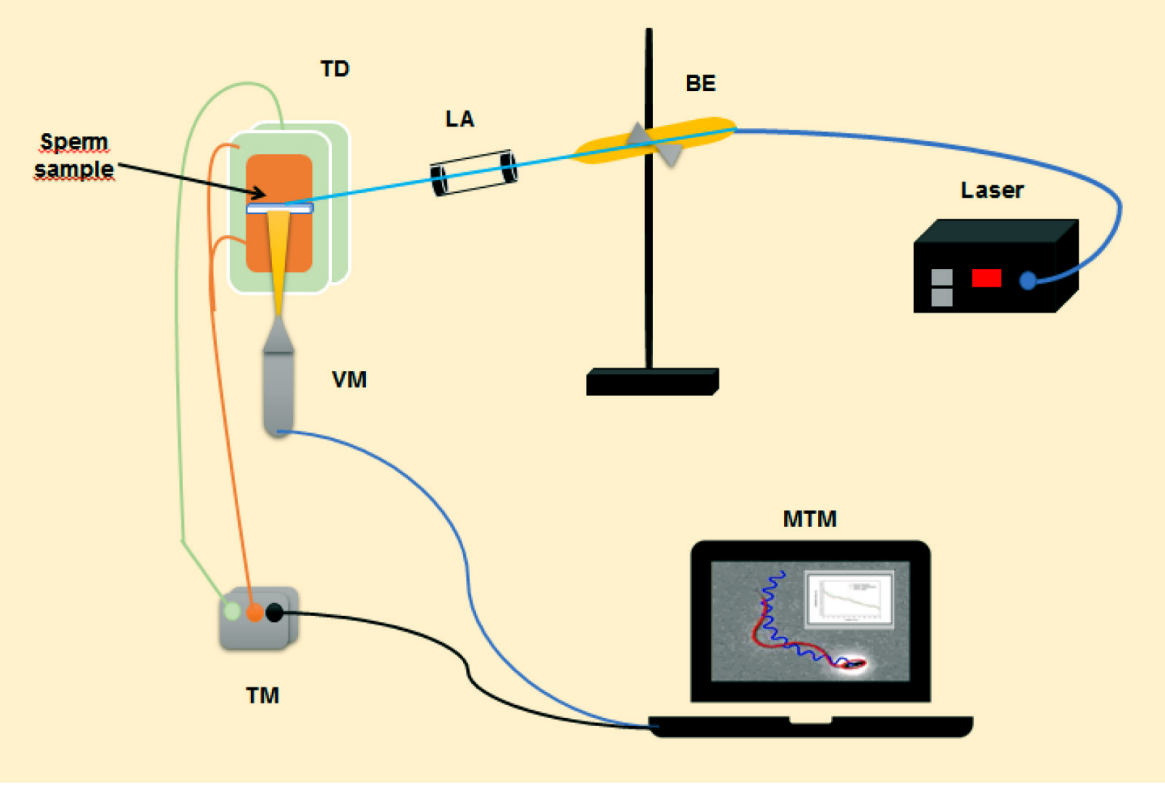

Sperm

Hyperactivation and Capacitation Induced By Light Stimuli in Cryopreserved Semen

Figure 1: Experimental setup. The sperm samples were placed on a glass slide that was enabled for measuring temperature. The samples were excited by our blue $405 \mathrm{~nm}$ laser, and the sperm motion was recorded with a high-resolution video camera. (BE) Beam expander, (LA) Lens array, (MTM) Monitor of temperature and motility, Sperm Simple, (TD) Thermoregulator, Device (TM) Temperature microcontroller and (VM) Video microscope.

status must be evaluated. To do so, the chlortetracycline (CTC) test, was carried out on the frozen-thaw samples, on the control (without irradiation), as well as on the two irradiated semen groups (60 and $90 \mathrm{sec}$ ). Following the method described by García-Macedo et al., (2001), with a few modifications. Briefly, one drop of $20 \mu \mathrm{l}$ of CTC solution (750 $\mathrm{mol}$ CTC, $130 \mathrm{mmol} \mathrm{NaCl}$, $5 \mathrm{mmol}$ cysteine and $20 \mathrm{mmol}$ tris- $\mathrm{Cl}, \mathrm{pH} 7.7$ ) was mixed with the same amount of semen, either irradiated or not. Then, semen-CTC samples were incubated during $30 \mathrm{sec}$. After that, $2 \mu \mathrm{l}$ of $12.5 \%$ glutaraldehyde in Tris- $\mathrm{HCl}$ solution ( 2 mmol, $\mathrm{pH} 7.8$ ) were added for fixation. Then, $10 \mu \mathrm{l}$ of this mixture was smeared on a warmed glass-slide, which was covered with $10 \mu \mathrm{l}$ of mounting media (PBS-Glycerol 1:1), and were observed under 100X magnification, in an epifluorescence microscope (Nikon, Eclipse 90i, Japan). One hundred cells per group were counted for capacitation status analysis of each experimental group, with three repetitions, classifying the three possible statuses: capacitated (B), non-capacitated (F), and acrosome reacted (AR). 
Soto, V

Fuentes, MA

Navidad, G

Meza, RN

Mandujano, LA

Salazar, AG

Fernández, C

García, C

Felipe-Pérez, YE

Osorio-González D

\subsection{Motility analysis}

The recorded videos were exported to extract each frame of the videos as a PNG image sequence using the open source software VirtualDub v1.10.4 and the FFMpeg Input plugin. To process and edit the image sequences, we used the open source software ImageJ v1.50i and the MosaicSuite Background Subtractor plugin. The image sequences were processed by applying different options.

We developed a JAVA plugin for ImageJ, similar to the commercial versions of a Computer Assisted Sperm Analyzer (CASA), which provide us information such as Curvilinear velocity (VCL), Straight line velocity (VSL), Average path velocity (VAP), Linearity (LIN) and Balancing (WOB).

\section{RESULTS AND DISCUSSION}

To carry out the motility study of both fresh and cryopreserved samples, the viscosity was estimated using high-resolution rheometry. The values were in the range of 0.008 and $0.014 \mathrm{~Pa}$.s for the fresh samples, while for the cryopreserved samples a range of $0.16-0.23 \mathrm{~Pa} . \mathrm{s}$ was obtained as shown in figure 2

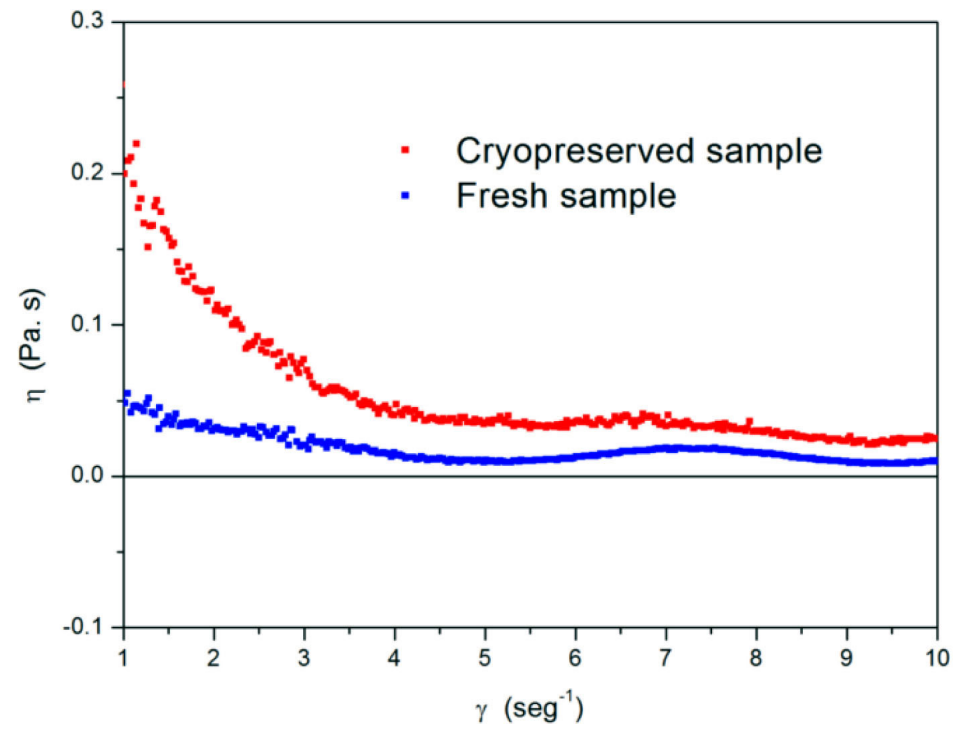

Figure 2: The graph compares the viscosity $(\boldsymbol{\eta})$ as function of shear rate $(\boldsymbol{\gamma})$ between a sample of fresh sperm (blue squares) and one that was previously cryopreserved (red squares). 
The viscosity values were used in the estimation of motility with CASA. Fresh samples were capacitated and analyzed. Table 1 shows the results and a significant increase in velocities was observed, the trajectories are not rectilinear and are in agreement with the normal parameters of motility

Concerning the cryopreserved samples, they were irradiated with a blue laser beam at 4.2 joules and 6.3 joules. We chose a power of $70 \mathrm{~mW}$ because this represents a less time of exposure of the sample and therefore a lower sperm stress due to changes in temperature. The results are shown in Table 2 , and we can see that the laser light stimulus effectively increases the sperm motility of the thawed samples

Table 1: Motility evaluation results of three Capacitated (C) and Non-Capacitated (NC) fresh sperm samples.

\begin{tabular}{lllllll}
\hline & Sample 1 & \multicolumn{2}{c}{ Sample 2 } & \multicolumn{3}{c}{ Sample 3 } \\
& C & NC & C & NC & C & NC \\
\hline $\begin{array}{l}\text { VCL } \\
(\mu \mathrm{m} / \mathrm{sec})\end{array}$ & $64.48 \pm 17.1$ & $54.66 \pm 15.2$ & $72.53 \pm 20.7$ & $61.06 \pm 15.18$ & $68.89 \pm 14.5$ & $57.88 \pm 19.1$ \\
VAP & $40.90 \pm 15.4$ & $37.39 \pm 11.6$ & $58.63 \pm 12.5$ & $50.59 \pm 17.4$ & $57.98 \pm 21.2$ & $41.98 \pm 15.7$ \\
$(\mu \mathrm{m} / \mathrm{sec})$ & & & & & & \\
$\mathrm{VSL}$ & $24.38 \pm 9.1$ & $14.31 \pm 6.3$ & $38.95 \pm 5.8$ & $35.66 \pm 11.1$ & $27.96 \pm 8.9$ & $25.78 \pm 9.0$ \\
$(\mu \mathrm{m} / \mathrm{sec})$ & & & & & & \\
$\begin{array}{l}\mathrm{LIN} \\
(\%)\end{array}$ & $59.62 \pm 20.6$ & $38.28 \pm 13.1$ & $50.37 \pm 14.2$ & $70.50 \pm 20.7$ & $55.89 \pm 14.9$ & $39.78 \pm 14.5$ \\
WOB & $63.42 \pm 15.4$ & $68.40 \pm 21.5$ & $51.87 \pm 17.6$ & $84.84 \pm 23.2$ & $59.23 \pm 21.5$ & $47.87 \pm 25.7$ \\
$(\%)$ & & & & & & \\
\hline
\end{tabular}

Table 2: Evaluation of motility in irradiated thawed sperm samples show that velocities increasing.

\begin{tabular}{llllc}
\hline & CONTROL & $\mathbf{4 . 2}$ JOULES & $\mathbf{6 . 3}$ JOULES & p \\
\hline VLS (um/s) & $0.8359 \pm 0.23$ & $13.6214 \pm 1.0005$ & $14.3342 \pm 0.71$ & $<0.05$ \\
VAP (um/s) & $0.9821 \pm 0.12$ & $18.8359 \pm 0.68$ & $17.8359 \pm 0.34$ & $<0.05$ \\
VCL (um/s) & $1.2699 \pm 0.31$ & $22.2184 \pm 1.3003$ & $23.0023 \pm 0.8769$ & $<0.05$ \\
LIN (\%) & $66.5 \pm 1.2$ & $61.32 \pm 1.8$ & $62.3 \pm 1.2$ & 0.003 \\
WOB (\%) & $77.9 \pm 2.1$ & $84.7 \pm 2.3$ & $73.9 \pm 2.7$ & 0.007 \\
\hline
\end{tabular}

To evaluate the effects of irradiation on capacitation, a CTC test was carried out and results in Table 3 are evidence that the stimulation of laser light in thawed samples favors capacitation 
Soto, V

Fuentes, MA

Navidad, G

Meza, RN

Mandujano, LA

Salazar, AG

Fernández, C

García, C

Felipe-Pérez, YE

Osorio-González D
Table 3: The percentage of spermatozoa non-capacitated (F) and capacitated (B), with three groups of irradiated spermatozoa with their corresponding repetitions $\mathrm{C} 1, \mathrm{C} 2$ and $\mathrm{C} 3$.

\begin{tabular}{ccccccc}
\hline & \multicolumn{3}{c}{$\begin{array}{c}\text { NON CAPACITED } \\
(\mathbf{F})\end{array}$} & \multicolumn{3}{c}{$\begin{array}{c}\text { CAPACITED } \\
(\mathbf{B})\end{array}$} \\
\cline { 2 - 7 } & \multicolumn{3}{c}{ Irradiation energy } & \multicolumn{3}{c}{ Irradiación energy } \\
\cline { 2 - 7 } & $\mathbf{0}$ & 4.2 Joules & $\mathbf{6 . 3}$ Joules & $\mathbf{0 ”}$ & 4.2 Joules & 6.3 Joules \\
\hline C1 & 12 & 13 & 5 & 28 & 53 & 60 \\
C2 & 19 & 9 & 5 & 28 & 66 & 64 \\
C3 & 14 & 12 & 4 & 29 & 56 & 61 \\
Media $=$ & 15 & 11 & 5 & 28 & 58 & 62 \\
\hline
\end{tabular}

On the other hand, to evaluate the possible damage due to irradiation a sperm vitality test was performed using an eosin-nigrosin staining. In this study, the membrane of the dead spermatozoa is permeable to the dye, and it is possible to observe the percentage of viable and non-viable spermatozoa. The results of Table 4 show that the sperm viability of the irradiated samples is affected between 15 and $22 \%$ compared to the nonirradiated samples

Similar studies have been reported that irradiation of human sperm with visible light (400-800 $\mathrm{nm}$ ) and reactive oxygen species (ROS) production is induced in mitochondria, activating the Src and EGFR proteins involved in sperm hyperactivation [19]. In a similar investigation, improve in bull (Bos taurus indicus) sperm motility, and acrosome membrane integrity after irradiation with red light $(660 \mathrm{~nm})$ was proved [5]. Also, treatment with red $(660 \mathrm{~nm})$ and white $(400-800 \mathrm{~nm})$ light was proved to increase motility and fertilization in tilapia sperm, while in ram sperm only red light effects have been observed. Additionally, the use of UV light $(294 \mathrm{~nm})$ and blue light $(360 \mathrm{~nm})$ generate a high amount of intracellular ROS which decreased motility and fertility in both species (Zan-Bar et al., 2005).

Table 4: Show the percentage of viable and non-viable spermatozoa for the three groups under study.

\begin{tabular}{ccc}
\hline Group & Viable spermatozoa $(\boldsymbol{\%})$ & Non-viable spermatozoa $(\boldsymbol{\%})$ \\
\hline 0 Joules & 48 & 52 \\
4.2 Joules & 37 & 63 \\
6.3 Joules & 41 & 59 \\
\hline
\end{tabular}




\section{CONCLUSIONS}

With our experiments, we could verify that the irradiation of cryopreserved sperm samples with a blue laser increases their motility and capacitation. This phenomenon could be explained by the fact that the procedure promotes the generation of reactive oxygen species (ROS) and this highly oxidative process increases tyrosine phosphorylation in sperm proteins and promotes such hyperactivation and sperm capacitation.

The increase in sample viscosity of thawed sperm affects their motility and promotes rectilinear trajectories with less oscillation. However, the capacitation and sperm viability are preserved moderately, suggesting that the stimulus of blue light in shorter periods of time could be a technique that contributes to thawing processes, of course without neglecting any careful study of possible DNA damage that complements the present study.

\section{ACKNOWLEDGMENTS}

The authors wish to thank CONACyT, COPARMEX and UNIVERSIDAD MEXIQUENSE for scholarship support, and Dra. Lorena Romero Salazar from Nanothermodynamics and Complex Systems Laboratory by granting facilities for the timely development of the project.

\section{REFERENCES}

[1] Dohle G.R., Diemer T., Giwercman A., Jungwirth A., Kopa Z., Krausz C. (2010). Guía clínica sobre la infertilidad masculina. European Association of Urology

[2] Tapia S. P. (2012). Una visión actual de la infertilidad masculina. Rev. Mex. Reprod. 4(3), 103-109

[3] Corral B. M. I., Rigau T., Rivera M., Rodriguez J. E., Rigau J. (2005). Effect of 655-nm diode laser on dog sperm motility. Lasers in Medical Science 20, 28-34

[4] Holt WV, Watson P, Curry M, Holt C. (1994). Reproducibility of computeraided semen analysis: comparison of five different systems used in a practical workshop. Fertil Steril 62, 1277-1282

[5] Fernandez GHC, de Carvalho PdTC, Serra AJ, Crespilho AM, Peron JPS, Rossato C, et al. (2015). The Effect of Low-Level Laser Irradiation on Sperm Motility, and Integrity of the Plasma Membrane and Acrosome in Cryopreserved Bovine Sperm. PLoS ONE 10(3): e0121487. doi:10.1371/journal.pone.0121487

[6] Lubart R, Levinshal T, Cohen N, Friedmann H y Breitbart H. (1996). Changes in Calcium Transport in Mammalian Sperm Mitochondria and Plasma Membrane due to $633 \mathrm{~nm}$ and $780 \mathrm{~nm}$ Irradiation. Laser in der Medizin / Laser in Medicine, 449-453.
Hyperactivation and Capacitation Induced By Light Stimuli in Cryopreserved Semen
Sperm

Semen 
Soto, V

Fuentes, MA

Navidad, $\mathrm{G}$

Meza, RN

Mandujano, LA

Salazar, AG

Fernández, C

García, C

Felipe-Pérez, YE

Osorio-González D
[7] Manchini MT, Serra AJ, Feliciano R dos S, Santana ET, Antônio EL, de Tarso Camillo de Carvalho P, et al. (2014). Amelioration of cardiac function and activation of anti-inflammatory vasoactive peptides expression in the rat myocardium by low-level laser therapy. PLOS One. Jul 3; 9(7):e101270.

Doi: 10. 1371/journal.pone.0101270 PMID: 24991808

[8] Juárez B. A., Díaz P. Ma. De los A., Sánchez M. M.,Flores E. X. E. y Acosta G. P. M. (2009). Capacitación espermática con doble eyaculado de corto intervalo. Una alternativa en reproducción asistida. Ginecol Obstet Mex 77(12), 550-555

[9] Oehninger S. (2010). Strategies for the infertile man. Sem Reprod Med; 19(3), 231-7.

[10] Agarwal A., Rakesh K. S. and Nelson D. R. (2003). New Semen Quality Scores Developed by Principal Component Analysis of Semen Characteristics, The Cleveland Clinic Foundation, Cleveland, Ohio. Journal of Andrology, Vol. 24, No. 3.

[11] Nilendran S. Prathalingam, Holt W. W., Revell S. G., Jones S.Y. and Watson P. F. (2006). The Precision and Accuracy of Six Different Methods to Determine Sperm Concentration, Journal of Andrology, Vol. 27, No. 2, 2006.

[12] García Macedo R., Rosales A. M., Hernández Pérez O., Chavarría M. E., Reyes A. and Rosado A. (2001). Effect of bafilomycin A1, a specific inhibitor of vacuolar (V-type) proton ATPases, on the capacitation of rabbit spermatozoa. Andrologia 33, 113-121

[13] Flaherty C. O. (2015). Redox regulation of mammalian sperm capacitation. Asian Journal of Andrology. 17, 583-590.

[14] Roldan-Schuth, E. R. S. (2010). Biología de la reproducción de mamíferos en peligro de extinción. REDVET. Revista electrónica de Veterinaria 1695-7504. Volumen 11 Número 07

[15] Hafez Y. M. (2015). Assisted reproductive technologies in farm Animals. ICMALPS, Alexandria University, Egypt

[16] Alonso S. M., Ramírez N. R. y Taylor P. J. de J. (2012). El cambio climático y su impacto en la producción de alimentos de origen animal (Climate change impacts on animal food production) Revista electrónica de Veterinaria - ISSN 1695-7504. Volumen $13 \mathrm{~N}^{\circ} 11$.

[17] Vuthiphandchai, V., Chomphuthawach, S.\& Nimrat, S., (2009). Cryopreservation of red snapper (Lutjanus argentimaculatus) sperm: Effect of cryoprotectants and cooling rates on sperm motility, sperm viability, and fertilization capacity. Theriogenology, 72(1), pp. 129-138.

[18] Rurangwa, E., Kime, D. E., Ollevier, F. \& Nash, J. P., 2004. The measurement of sperm motility and factors affecting sperm quality in cultured fish. Aquaculture, Volumen 234, pp. 1-28. 
[19] Shahar, S., Hillman, P., Lubart, R., Ickowicz, D., \& Breitbart, H. (2014). Activation of sperm EGFR by light irradiation is mediated by reactive oxygen species. Photochemistry and Photobiology, 90(5), 1077-1083.

[20] Zan-Bar, T., Bartoov, B., Segal, R., Yehuda, R., Lavi, R., Lubart, R., \& Avtalion, R. R. (2005). Influence of visible light and ultraviolet irradiation on motility and fertility of mammalian and fish sperm

Sperm

Hyperactivation and Capacitation Induced By Light Stimuli in Cryopreserved

Semen 